\title{
PERSONAL ETHICS OF TODAY'S SPORT FANS: \\ CONNECTING CULTURAL VALUES, ETHICAL IDEOLOGIES, AND ETHICAL INTENTIONS
}

\author{
Brent Smith, Saint Joseph's University, United States of America \\ John Lord, Saint Joseph's University, United States of America
}

\begin{abstract}
The fanatics of sport are highly engaged participants and observers who can stir excitement, or ire, among others within their midst. In reference to sport fanatics, Mike Schmidt, a former player for Philadelphia Phillies professional baseball team, once declared, "They read their sports pages, know their statistics and either root like hell or boo our butts off. I love it. Give me vocal fans, pro or con, over the tourist types who show up in Houston or Montreal and just sit there."

Mainstream competitive sports, such as basketball, American football, baseball, and soccer, have attracted the attention of consumers around the world. Aside from the athletes and referees who craft the play of these sports, the fans who watch and react to them represent an equally integral feature of the overall sport experience. More than simply spectators, fans are prosumers (producers and consumers) who have the potential to affect that experience for other fans, athletes, and officials.
\end{abstract}

While fans are expected to express their emotions, evaluations, and expectations in the sporting arena/court/field, opinions vary about whether certain fan expressions can be deemed inappropriate, excessive, or even offensive. In this study, we examine whether sport fans' personal cultural values and ethical ideologies influence their reactions -- ethical perceptions and ethical intentions - to questionable fan behaviors.

Essentially, the sport community understands that favorable fan experiences are vital to the success of all sports. As a result, sport leagues, team owners, venue managers, and fans have a keen interest in maintaining a welcoming climate for all spectators. Questionable fan behaviors represent potential annoyance, or menace, to that climate, particularly for fans attending with spouses, children, and families. All stakeholders participating in the sport experience - whether at, on, and near the arena/court/field of play - have a collective responsibility to foster an environment free from indecent language, abusive behaviors, disruptive acts, and various forms of disrespectful conduct.

In light of the globalization of various sports and the growth of consumer cultures surrounding them, the study of cultural values and ethical ideologies among sport fans is important for understanding the sorts of behavior that fans expect of themselves and their peers. Given that these fans prosume elements of the sport experience, such an understanding can help inform how decision makers set rules and conditions for appropriate spectating. The results of this research do not offer specific remedies for unacceptable fan behavior; however, they do provide some basic insights into how individuals' personal values and moral positions can influence their perceptions and evaluations of various fan behaviors.

References Available Upon Request 